\title{
Combline Bandstop Filter Design and Analysis using Bandstop MEMS Switching
}

\author{
Alpana Singh \\ M.Tech Scholar, Subharti University, \\ Meerut, U.P. India.
}

\author{
Tejbir Singh \\ Assistant Professor, EC Department \\ Subharti University, Meerut, U.P. India.
}

\begin{abstract}
In this paper different band stop filter topologies have been proposed using MEMS to achieve compactness in comparison with the same class of filter topologies available in literatures. A shift in resonance characteristics and bandwidth is reported by using MEMS switch at various positions. All simulations are carried out using Ansoft HFSS and CST MWS.
\end{abstract}

Keywords

Bandstop filter, MEMS, HFSS, Bandwidth

\section{INTRODUCTION}

The promising field of MEMS technology has been evolved from the integrated circuit industry. The most intrinsic characteristics are miniaturization, microelectronics integration, and accurate mass production. MEMS technology facilitates it possible to manufacture electromechanical and microelectronics component in a single tiny device ranging from $1 \mu \mathrm{m}$ to $1 \mathrm{~mm}$. The decrease in dimension of electromechanical systems provides benefits like more reliability, more resonant frequency, and low thermal mass, and hence, there exist significant reduction in power consumption.

In MEMS, while the electronics are manufactured by employing integrated circuit processes, the micromechanical components are constructed using micromachining processes that selectively etch away silicon wafer parts or make more structural layers to form the electromechanical devices. The mechanical sensors and actuators, and electronic controllers and microprocessors have been demonstrated to be fabricated on a single substrate. Lithography guarantees the accurate dimension and position. The batch based fabrication processes have the possibility to get large volume fabrication and therefore, there is reduction in expenditure and considerable enhancement in the yield and reliability.

A band stop filter (BSF) also known as band reject filter can be defined as a network that passes most frequencies unaltered and attenuates those in a specific range to very low levels. A special kind of band stop filter is the notch filter (or wave trap) which is a narrowband band stop filter.

In the recent days researchers all over the world took keen interest to develop different planar band stop filters which are compact in size by employing defective ground, coupled resonators, microstrip line with spiral resonators cut on the line etc. This chapter presents various BSF structures developed using planar technology using MEMS to achieve compact size. Few structures of band stop filter have been presented using the defective ground with mushroom structures in various literature. It uses a multilayer structure to achieve compactness.

\section{WIDE BANDSTOP FILTER DESIGN USING MEMS LINES}

A band stop filter may be designed by using the shunt quarterwavelength (at the mid-stop band frequency) long opencircuited stubs separated by a quarter wave length long (at the mid-stop band frequency) transmission line [1] - [3],. The basic structure of the optimum band stop filter [2], [14], [15], is based on the open circuited transmission line stub network as depicted in figure (5.1). Filtering characteristics of this filter entirely depend on the design of characteristic impedances $Z_{i}$ for the open-circuited stubs, characteristic impedances $Z_{i, i+1}$ for the transmission line elements and two terminating impedances $\mathrm{Z}_{\mathrm{A}}$ and $\mathrm{Z}_{\mathrm{B}}$ [2]

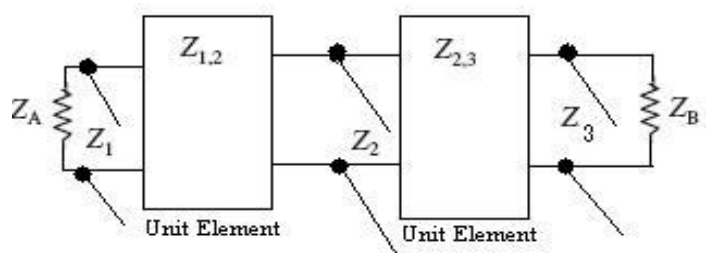

Fig.1. Transmission line network representation of open stub band stop filter.

The design equations are given here for easy reference from [2]. The synthesis of the ladder network shown in figure (1) is based on following transfer function given by equation (1).

$$
\left|S_{21}(f)\right|=\frac{1}{1+\varepsilon^{2} A_{n}^{2}(f)}
$$

Where $\varepsilon$ is the pass band ripple constant and $A_{n}$ is the filtering function represented by the following:

$$
A_{n}(f)=B_{n}\left(\frac{t}{t_{c}}\right) B_{n-1}\left(\frac{t \sqrt{1-t^{2}}}{t_{c} \sqrt{1-t^{2}}}\right)-C_{n}\left(\frac{t}{t_{c}}\right) C_{n-1}\left(\frac{t \sqrt{1-t^{2} c}}{t_{c} \sqrt{1-t^{2}}}\right)
$$

Where $t$ and $t_{c}$ are the Richards' transform variables which are given by

$$
\begin{aligned}
t=j \tan \left(\frac{\pi}{2} \frac{f}{f_{o}}\right) & \\
t_{c} & =j \tan \left(\frac{\pi}{2}(2-F B W)\right)
\end{aligned}
$$


The fractional band width of the filter is defined as:

$$
\begin{aligned}
& F B W=\frac{f_{2}-f_{1}}{f_{o}} x 100 \% \\
& B_{n}(x)=\cos \left(n \cos ^{-1} x\right) \\
& C_{n}(x) \sin \left(n \cos ^{-1} x\right)
\end{aligned}
$$

where $\mathrm{f}_{0}$ is the mid-band frequency of the band-stop filter. $\mathrm{B}_{\mathrm{n}}(\mathrm{x})$ and $\mathrm{C}_{\mathrm{n}}(\mathrm{x})$ used in equation (2) are the Chebysheve functions of the first and second kinds respectively of order $n$. The impedances $\mathrm{Z}_{\mathrm{A}}, \mathrm{Z}_{\mathrm{B}}, \mathrm{Z}_{\mathrm{i}}$ and $\mathrm{Z}_{\mathrm{i}, \mathrm{i}+1}$ are defined as:

$$
\begin{array}{r}
Z_{A}=Z_{B}=Z_{o} \\
Z_{i}=Z_{\delta} / g_{i} \\
Z_{i, i+1}=Z_{\delta} / J_{i, i+1}
\end{array}
$$

Where $g_{i}$ and $J_{i, i+1}$ are the element values of the lowpass prototype and admittance inverters respectively. An optimum microstrip band-stop filter with three open-circuited stubs and a fractional bandwidth FBW $=100 \%$ at a mid-band frequency $\mathrm{f}_{0}=3 \mathrm{GHz}$ is designed. By considering a pass band return loss of $-20 \mathrm{~dB}$, which corresponds to a ripple constant $\varepsilon=0.1005$. For optimized filter the normalized element values are taken from [2] which are $\mathrm{g}_{1}=\mathrm{g}_{3}=0.94806, \mathrm{~g}_{2}=1.67311$, and the impedance inverters $J_{1,2}=J_{2,3}=0.56648$. The filter is designed to match $50 \mathrm{ohm}$ terminations. Therefore $\mathrm{Z}_{0}=50$ ohms, and from equation (5.8) we determine the electrical parameters for the desired filter network. The parameters values so obtained are given below:

$$
\begin{gathered}
Z_{A}=Z_{B}=50 \text { ohms } \\
Z_{1}=Z_{3}=52.74 \text { ohms } \\
Z_{2}=29.88 \text { ohms } \\
Z_{1,2}=Z_{2,3}=88.26 \text { ohms }
\end{gathered}
$$

The lengths and widths of the corresponding microstrip line open stubs are determined by using the equation from (5) to (7). The BSF so obtained is shown in figure (5.2) along with their dimensional values. The width of the microstrip lines connected with two open ended stubs are $0.45 \mathrm{~mm}$ and width of the $50 \mathrm{ohm}$ microstrip line is $1.82 \mathrm{~mm}$.

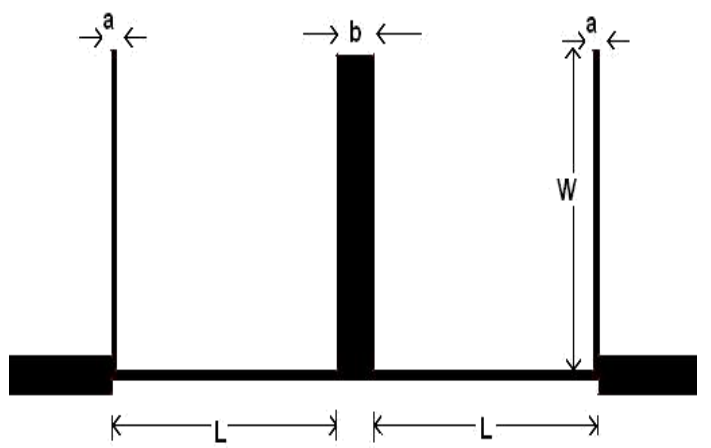

Fig 2. Microstrip BSF with optimum design with $\mathbf{a}=$ $0.3 \mathrm{~mm}, \mathrm{~b}=2.3 \mathrm{~mm}, \mathrm{~W}=15.15 \mathrm{~mm}, \mathrm{~L}=15.5 \mathrm{~mm}$.

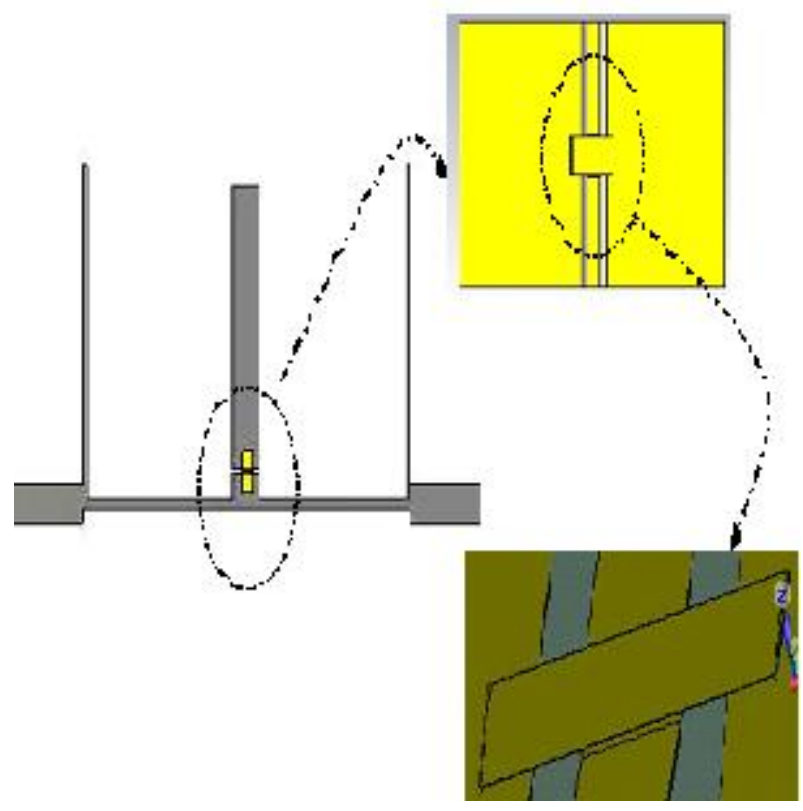

Fig3. Microstrip BSF with optimum design with $\mathbf{a}=$ $0.3 \mathrm{~mm}, b=2.3 \mathrm{~mm}, W=15.15 \mathrm{~mm}, \mathrm{~L}=15.5 \mathrm{~mm}$.

\section{SIMULATION OF MEMS BANDSTOP FILTER}

The above figure shows the structure of BSF. which is simulated using Ansoft HFSS. Fig. 3, 5 and 9 illustrate the simulated design using HFSS.

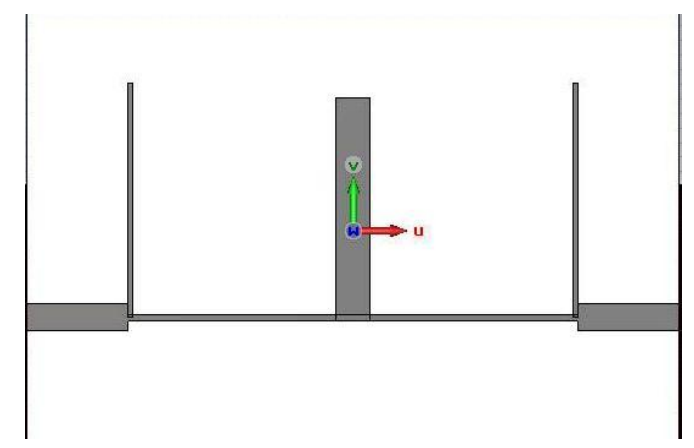

Fig4. Microstrip BSF with optimum design with $\mathrm{a}=$ $0.3 \mathrm{~mm}, \mathrm{~b}=2.3 \mathrm{~mm}, \mathrm{~W}=15.15 \mathrm{~mm}, \mathrm{~L}=15.5 \mathrm{~mm}$.

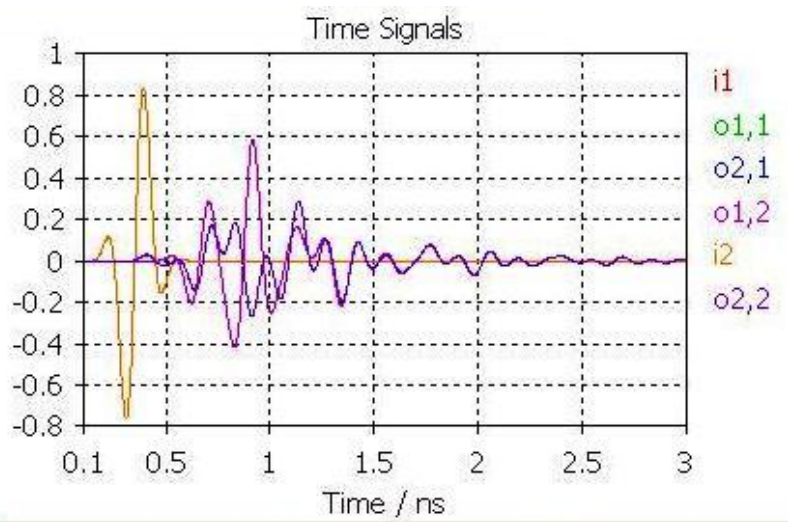

Fig 4. Excitation Signal 
Fig.5 shows the excitation signal and the output signal at port number 1 and 2 . It clearly shows that there is symmetry between port number 1 and 2 .

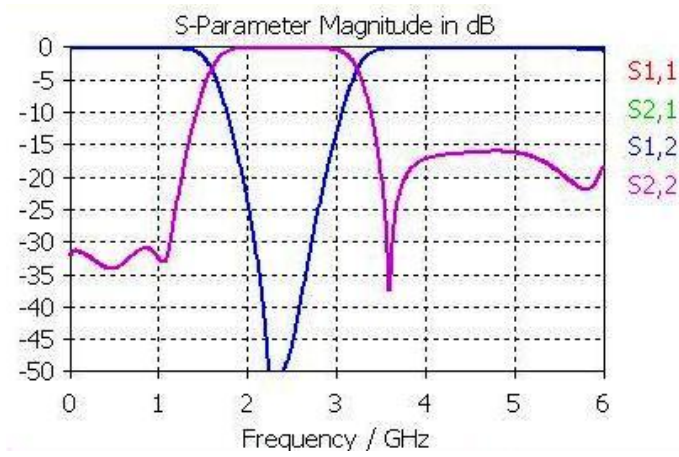

Fig 6. S- Parameter curve for design 1 (without MEMS)

The above design shows the resonance $S(1,2)$ between the frequencies ranging from 1 to $3 \mathrm{GHz}$. It shows that when both the switches are opened then the designed filter stop the band having frequency range from $1.8 \mathrm{GHz}$ to $3.4 \mathrm{GHz}$.



Fig7. Microstrip BSF with optimum design with a = $0.3 \mathrm{~mm}, b=2.3 \mathrm{~mm}, W=15.15 \mathrm{~mm}, \mathrm{~L}=15.5 \mathrm{~mm}$. (MEMS Switch between left and centre stub)

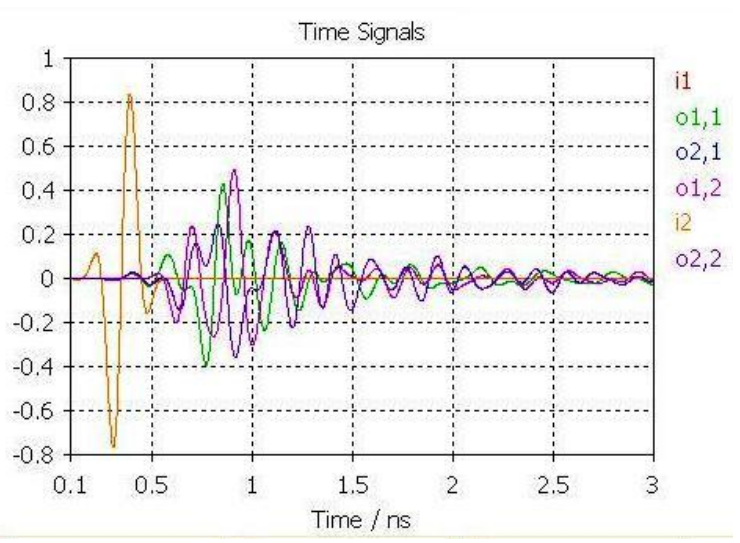

Fig 8. Excitation Signal (MEMS-design1)

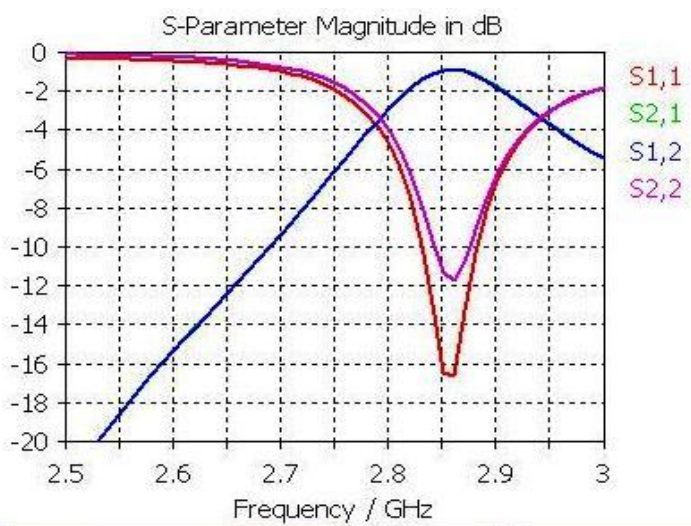

Fig 9. S- Parameter curve for design (MEMS Switch between left and centre stub)

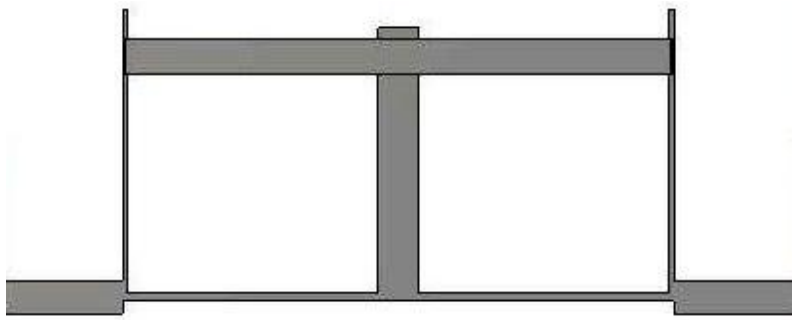

Fig 10. Microstrip BSF with optimum design with a = $0.3 \mathrm{~mm}, b=2.3 \mathrm{~mm}, \mathrm{~W}=15.15 \mathrm{~mm}, \mathrm{~L}=15.5 \mathrm{~mm}$. (MEMS Switch between left and right stub)

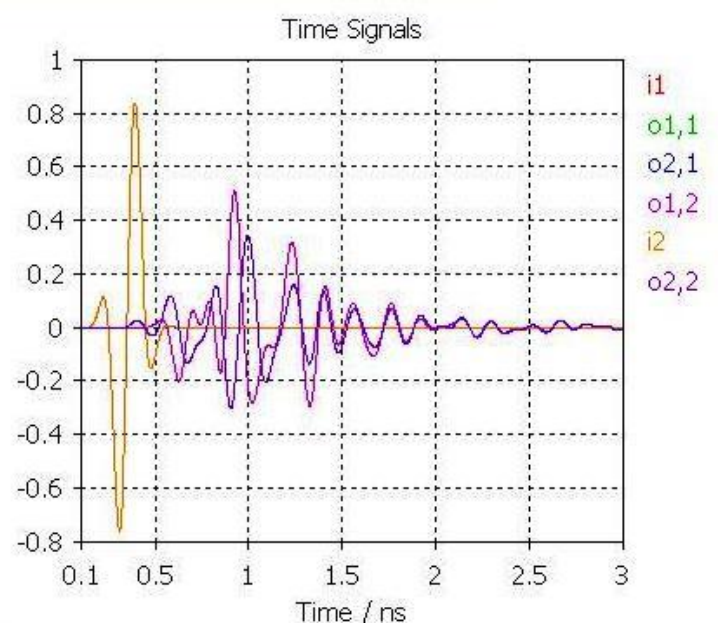

Fig 11. Excitation Signal (MEMS-design2)

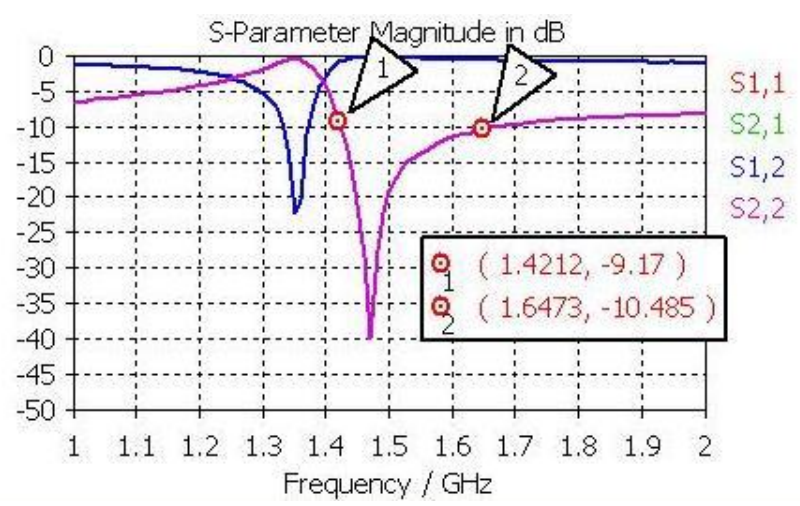

Fig 12. S- Parameter curve for design (MEMS Switch between left and centre stub)



Fig 13. S- Parameter curve for design (MEMS Switch between left and centre stub) 


\section{CONCLUSION}

The proposed design shows the resonance $S(1,2)$ between the frequencies ranging from 1.2 to $1.50 \mathrm{GHz}$. It shows that when the MEMS switch between both the left and right with center stub is closed then the designed filter stop the band having frequency range from $1.33-1.38 \mathrm{GHz}$ The designs also shows the resonance $S(1,2)$ is between the frequencies ranging from 2.5 to $3.0 \mathrm{GHz}$ having return loss upto $-17 \mathrm{~dB}$. It also shows that when the MEMS switch between left and center stub is closed and right one is opened then the designed filter stop the band having frequency range from $2.8 \mathrm{GHz}$ to $2.9 \mathrm{GHz}$.

\section{ACKNOWLEDGEMENT}

I express my sincere and heartfelt gratitude to my supervisor Mr. Tejbir Singh, for his invaluable suggestions and inspiring guidance and above all her limitless patience. I thank her for being instrumental in making this project a great success. At the outset I would like to express my immense gratitude to our Principal Dr. Jayant Shekhar for all the facilities provided by him for the successful completion of the project work. I am also grateful to Mr. Amit Choudhary, M. Tech. Convener for providing proper information at right time for the successful completion of this project. I would also like to thank Mr. Dharmendra Verma for reviewing the project, for his kind co-operation and valuable suggestions.

\section{REFERENCES}

[1] R. Garg, P. Bhartia, I. Bahl, and A. Ittipibon, Microstrip Antenna Design Handbook, Artech House, Boston London, 2001.

[2] D. Morgan and R. Ragland, "Lumped element filters for electronic warfare systems," Microwave J., vol. 29, pp. 127-136, Feb. 1986.

[3] R. Levy, "Design considerations for lumped-element microwave filters," Microwave J., vol. 31, pp. 183-192, Feb. 1988.

[4] S. B. Cohn, "Direct-coupled resonator filters," Proc. IRE, vol. 45, pp. 187-196, Feb. 1957.

[5] H. J. Orchard and G. C. Temes, "Filter design using transformed variables," IEEE Trans. Circuit Theory, vol. CT-15, pp. 385-408, Dec. 1968.

[6] G.L. Matthaei, L.Young, and E. M. T. Jones,Microwave Filters, Impedance-Matching Networks and Coupling Structures. New York: McGraw-Hill, 1964.

[7] R. Levy, "Direct synthesis of cascaded-quadruplet (CQ) filters," IEEE Trans. Microwave Theory Tech., vol. 43, pp. 2940-2945, Dec. 1995.

[8] G. L. Matthaei, "Comb-line band-pass filters of narrow or moderate bandwidth," Microwave J., vol. 6, pp. 8291, August 1963.

[9] I.C. Hunter and J. D. Rhodes, "Electronically tunable microwave bandpass filters," IEEE Trans. Microwave Theory Tech., vol. MTT-30, pp. 1354-1360, Sept. 1982.
[10] B. Easter and K. A. Merza, "Parallel-coupled-line filters for inverted-microstrip and suspended-substrate MIC's," in 11th Eur. Microwave Conf. Dig., September 1981, pp. 164-167.

[11] G. L. Matthaei, N. O. Fenzi, R. Forse, and S. Rohlfing, "Hairpin-comb filters for HTS and other narrow-band applications," IEEE Trans. Microwave Theory Tech., vol. 45, pp. 1226-1231, Aug. 1997.

[12] J-S. Hong and M. J. Lancaster, "Couplings of microstrip square open-loop resonators for cross-coupled planar microwave filters," IEEE Trans. Microwave Theory Tech., vol. 44, pp. 2099-2109, Nov. 1996.

[13] B. M. Schiffman and G. L. Matthaei, "Exact design of band-stop microwave filters," IEEE Trans. Microwave Theory Tech., vol. MTT-12, pp. 6-15, Jan. 1964.

[14]H. C. Bell, "resonator bandstop filters," IEEE Trans. Microwave Theory Tech., vol. 44, pp. 2669-2672, Dec. 1996.

[15] J. A. Curtis and S. J. Fiedziuszko, "Miniature dual mode microstrip filters," in IEEE MTT-S Int. Microwave Symp. Dig., vol. II, June 1991, pp. 443-446.

[16] J-S. Hong and M. J. Lancaster, "Theory and experiment of novel microstrip slow-wave open-loop resonator filters," IEEE Trans. Microwave Theory Tech., vol. 45, pp. 2358-2365, Dec. 1997.

[17]S. B. Cohn, "Microwave filters containing highdielectric resonators," IEEE Trans. Microwave Theory Tech., vol. MTT-16, pp. 218-227, Apr. 1968.

[18] S. J. Fiedziuszko, "Dual-mode dielectric resonator loaded cavity filters," IEEE Trans. Microwave Theory Tech., vol. MTT-30, pp. 1311-1316, Sept. 1982.

[19] A.Fukasawa,"Analysis and composition of a new microwave filter configuration with inhomogeneous dielectric medium," IEEE Trans. Microwave Theory Tech., vol. MTT-30, pp. 1367-1375, Sept. 1982.

[20] J. P. Rooney and L. M. Underkofler, "Printed circuit integration of microwave filters," Microwave J., vol. 21, pp. $68-73$, Sept. 1978.

[21]R. Levy, "Tapered corrugated waveguide lowpass filters," IEEE Trans. Microwave Theory Tech., vol. MTT-21, pp. 526-532, Aug. 1973.

[22] R. Levy, "Corrections to 'Direct synthesis of cascadedquadruplet (CQ) filters'," IEEE Trans. Microwave Theory Tech., vol. 45, p. 1517, Aug. 1996.

[23] N. Yang, C. Caloz, and K.Wu, Co-designed CPS UWB filterantenna system, in Proc. IEEE AP-S Int. Symp., pp. 1433- 1436. Jun. 2007 